\section{Study of Hydrogen Station Installation Utilizing Wind Power: Case study in Hokkaido}

\section{Kenji Niwa ${ }^{* a}$, Benjamin McLellan ${ }^{a}$, Tetsuo Tezuka ${ }^{\mathrm{a}}$}

${ }^{a}$ Graduate School of Energy Science, Kyoto University

Received: May 25, 2016/ Accepted: December 6, 2017

\begin{abstract}
Fuel cell vehicles (FCV) are a promising technology for Japan to achieve GHG emissions reduction and a selfsufficient energy system, but they have not been installed to a significant extent because of the "Chicken and Egg" dilemma between the roll-out of FCV and hydrogen stations. This research aims to identify the conditions under which hydrogen stations can be installed as economically feasible and continue to be utilized after installation with the initial level of hydrogen use. In order to achieve these aims, the hydrogen station business model is integrated with wind power, taking advantage of low marginal costs of this form of electricity generation. Considering the objectives of business, profit optimization of the business model is targeted. The results are analysed in three steps. Firstly, whether the business model provides incentive for investment. Secondly, whether the hydrogen station is utilized after its construction. Finally, through the analysis of the change in the local economy and in $\mathrm{CO}_{2}$ emissions caused by the energy system, the feasibility of the model is reinforced. From the analysis, it is suggested that by taking advantage of the low marginal cost of wind power, hydrogen stations can be utilized profitably while having positive impacts on the local economy and $\mathrm{CO}_{2}$ emissions.
\end{abstract}

Keywords: Fuel cell vehicle, Hydrogen, Renewable Energy, Local Economy, $\mathrm{CO}_{2}$ Emissions, Transportation

Abbreviations:
\begin{tabular}{|lcl|}
\hline 3EID & $:$ & Embodied Energy and Emission Intensity \\
& & Data for Japan Using IO-Tables \\
CAS & $:$ & Cabinet Secretaariat, Japan \\
FCV & $:$ & Fuel Cell Vehicles \\
GAMS & $:$ & The General Algebraic Modeling System \\
GHG & $:$ & Greenhouse Gas \\
IO-table & $:$ & Input Output Table \\
LCOE & $:$ & Levelised Cost of Electricity \\
METI & $:$ & Ministry of Economy, Trade and Industry, \\
& & Japan \\
MLIT & $:$ & Ministry of Land, Infrastrucutre, \\
& & Transport and Tourism, Japan \\
MOE & $:$ & Ministry of Environment, Japan \\
\hline
\end{tabular}

\section{Introduction}

Sustainability requires that society's impact on the environment is reduced from the present, particulary with regards to greenhouse gas emissions. Renewable energy may be one key element of sustainable energy futures, but there are a number of challenges to its integration in the current energy mix and expansion. Hydrogen is one promising technology which may contribute to meeting the challenges of renewable energy installation, particularly providing a storage medium for reducing issues of intermittency. Energy is a vital lifeline of society and, in addition to the potential environmental impacts, Japan is facing a problem in its energy system. Since the nuclear disaster in Fukushima in 2011, the energy consumption in Japan has been depending on imported fossil fuel at a rate of almost $90 \%$ of primary energy consumption according to the Ministry of Trade and Industry (METI) [1]. This is problematic not only in terms of GHG emissions and energy security, but also from a point of view of the national trade deficit. According to METI [2], imports of fossil fuels in 2013 reached approximately 27 Trillion JPY and this contributed significantly to the country`s largest trade deficit ever, 11 Trillion JPY.

Moreover, imports of fossil fuel are also placing an economic burden on local economies in the form of an outflow of cash. For example, the net imports of Kochi prefecture in 2010, which means the outflow of cash to other areas or countries, were 663 Billion JPY and $16 \%$ of these net imports were due to purchases of oil and coal [3]. In order to address this problem, renewable energy may play an important role due to the potential available within each local area. By utilising local renewable resources, significant improvements in the current situation may be achieved.

In terms of transportation, FCV are one important technology available to meet this problem of energy import dependence. In the context of the GHG reduction target for 2030 published by the Japanese government, which aims for $27.5 \%$ reduction from the transportation sector [4], 56\% of energy consumption in the transportation sector is shown to utilise gasoline [5]. Because FCV can reduce $\mathrm{CO}_{2}$ emissions significantly when hydrogen is produced using renewable resources such as wind power, they may be able to replace gasoline vehicles and help achieve this target. However, FCV have not been installed to any great extent to date. One of the reasons is the difficulty of rolling-out infrastructure. FCV expansion is a typical "Chicken and Egg" dilemma. For example, if there are only a few hydrogen stations, consumers may be reluctant to buy FCV because it is inconvenient to refuel. On the other hand, if there are no FCV purchases, no one wants to build hydrogen stations because it is not an attractive business. Thus, an attractive business model is necessary - particularly in the early stages of FCV installation.

For feasible hydrogen station installation, the initial cost should be recovered through the project period. This condition is expressed as Eq. (1), where Sales $(t)$ is the hydrogen sales during year $t, R \operatorname{Cost}_{(t)}$ is the operational expenditure of the hydrogen related equipment during year $t$, which does not include the depreciation of capital expenditure, and ICost is the capital expenditure of the project. 
$I r$ is the interest rate offered for investment. If the profit ratio from the project against the capital expenditure is lower than the discount rate through the project period, the investment will not be undertaken and the capital is maintained as a cash deposit to gain interest from the bank.

$$
\sum_{t}\left[\operatorname{Sales}_{(t)}-R \operatorname{Cost}_{(t)}\right]>I \operatorname{Cos} t \times(\operatorname{Ir})^{t}
$$

Because the cost recovery through the project period is still difficult for stand alone hydrogen stations, this paper considers the cost recovery in combination with wind power.

From the background and assumptions above, this research mainly focuses on three points. Firstly, this research focuses on hydrogen use for FCV. As mentioned, replacing gasoline with renewable energy-based hydrogen may contribute not only to reduction of GHG emissions but also to reduction of imports of oil. Because a model for hydrogen station installation is particularly important at the early stages, this research especially analyses the feasibility of a suitable model for introduction of FCV installation according to two criteria (whether hydrogen stations are installed and whether they are utilized after construction).

Secondly, this research focuses on wind power to combine with hydrogen stations in the business model. Wind power may contribute to recovering the initial cost of installation in the business model, because the levelised cost of electricity (LCOE) of onshore wind power in Japan is cost competitive with other resources [6]. LCOE of onshore wind power lies between 9.9 and 17.3 JPY / kWh and this is lower than oil thermal power, which is between 22.1 and 25.1 JPY / $\mathrm{kWh}$. The other reason is that as the marginal cost of wind power is low, the running costs can be reduced for the hydrogen production business. Thus, this research assumes an energy system in which hydrogen is produced from wind power and provided to fuel cell vehicles through hydrogen stations.

In addition to the economic feasibility of the business model, considering the purpose of this research, this system should have a positive impact on the local economy and environment (GHG emissions as a proxy here). In order to evaluate these aspects, inventory analysis was combined with the Input-Outpt (IO) table and 3 EID [18], which gives the "sectoral embodied environmental burden intensities calculated using Japanese input-output tables" [18]. The IO table is used to calculate the economic impact of a certain change in economic demand created in the system. The optimization program utilised here, calculates the newly created demand on the system, for example produced hydrogen. Then, by inputting the results of the optimization into the IO table, the impact on the local economy and GHG emissions are examined.

Finally, this research chooses Hokkaido as a case study. According to the Ministry of Environment (MOE) [7], Hokkaido has the largest potential for wind power in Japan. In addition to this, FCV might be more promising than Electric Vehicles (EV) (one competing technology) specifically in Hokkaido. EV are also a technology which enables the utilization of renewable energy for transportation. However, on the point of range of travel possible on one charge, FCV are generally superior [8]. Moreover, EV have two disadvantages in cold weather (common in Hokkaido, as the northermost prefecture of Japan). One is that the energy consumption for running the air conditioner shortens the range (unlike fuel-based vehicles which typically use waste heat from combustion to produce heating). The other is that under low temperature conditions, the specifications of batteries tend to become lower; including longer time to charge and shorter range than normal conditions [9].
Taking the above into consideration, this research aims to demonstrate that the situation where hydrogen stations are introduced and utilized after construction is feasible considering the current cost-technological standards. In addition, by confirming that the partial replacement of the current energy system by wind power and hydrogen have a positive impact on the local economy and GHG emissions, the feasibility of the energy model is expected to be reinforced.

This research is considered to offer two points of originality in comparison to studies to date. One is the division of the business model of hydrogen use into two parts: investment and utilization. The other is to examine integration of hydrogen production and wind power, which may enable the business model to take advantage of wind power's low marginal cost.

\section{Methodology}

In order to examine the feasibility of hydrogen station installation using wind power, the analysis is divided into four parts. The first is the design of the energy system. This is done using qualitative criteria. Then, once the system is designed, it is analysed using three quantitative methods: a profit optimization program using linear programing, an economic ripple effect analysis using economic input-output (IO) tables and life cycle assessment of $\mathrm{CO}_{2}$ emissions. This section presents the methodology of the analysis in detail.

\subsection{Design of Energy System Model}

As discussed already, this research examines a hydrogen station energy system model combined with wind power use. The system model is described in Figure 1. In this model, as a business model, a part of the electricity generated from wind power is sold to the electricity market and the rest is supplied to produce hydrogen using an electrolyser, then stored and provided to consumers with FCV via hydrogen stations. As a system boundary, storage devices other than hydrogen and accommodating electricity demand outside Hokkaido are not considered.

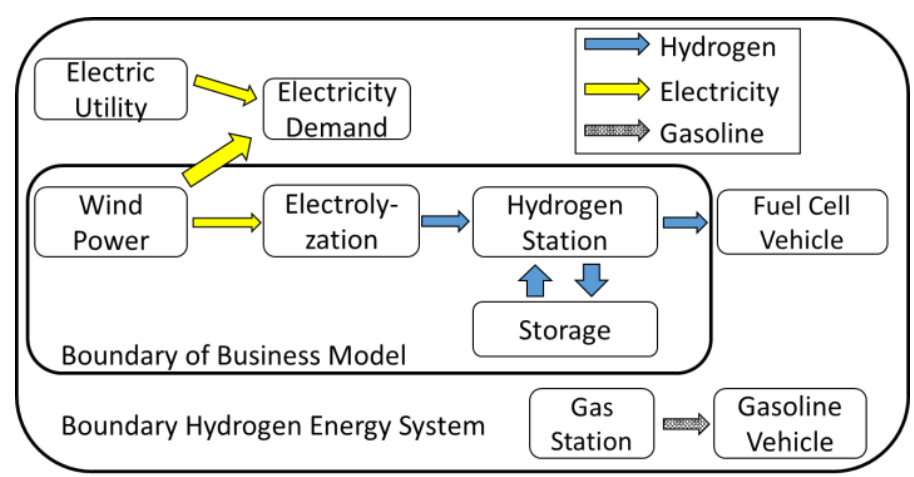

Figure 1 Energy System and Business System Model in This Study

\subsection{Optimization program}

In order to evaluate the model, the objective of the business is taken to be: maximisation of profit under a given scenario. A profit maximization program was designed, which provides various parameters as outputs to analyse the conditions for hydrogen introduction from the viewpoint of a company. The time scope of the optimization program is set as one year. Because the lifetime of each equipment item is different, in order to calculate the capital expenditure on equipment more precisely, and to annualise the costs, the capital expenditure on each equipment item is divided by its lifetime. In addition, because the total project period 
is not set in this optimization program, and in order to provide a consistent match with the IO table, a discount rate is not considered. As the objective function, profit from the business model is defined as Eq. (2), where HSales is the sales of hydrogen, ESales is the sales of electricity, Capex is the depreciation of capital expenditure on each piece of equipment including wind turbines, electrolyser and hydrogen station, and Opex is the operational expenditure on each equipment item. All are measured in monetary units. $i$ indicates each item of equipment: wind turbine, electrolyser and hydrogen station.

$$
\text { HSales + ESales }-\sum_{i} \operatorname{Capex}_{(i)}-\sum_{i} \operatorname{Opex}_{(i)}
$$

Three important constraints and parameters are applied to the model, and are briefly introduced below.

\section{Electricity Demand and Supply}

It is considered as a primary important condition that demand and supply of electricity always balance. Electricity demand refers to the actual hourly data in 2014 provided by Hokkaido Electric Power Company (HEPCO) [10]. Electricity supply is defined as the sum of electricity from wind turbines in this business model and electricity provided by sources outside of the business model. When electricity supply exceeds the demand for hydrogen production and other loads, the excess electricity can be wasted in order to maintain a balance. In other words, electricity supply has flexibility as long as the electricity demand for hydrogen production is satisfied. Electricity supply from wind turbines, at the same time, determines the sales of electricity with a base-case assumed price set as $15 \mathrm{JPY} / \mathrm{kWh}$.

\section{Electricity Supply from wind turbine}

Wind turbines are located at 14 places in each "Shicho" (subprefectural governing unit) of Hokkaido, in order to avoid the allocation of wind turbines being concentrated in one place, and wind turbines are allocated to these 14 places as a result of the optimization program in order to best achieve profit and match demand. The output of wind turbines in each place is determined by the wind velocity. The function between wind velocity and electrical output is derived from the actual behaviour of wind turbines described in the literature [11]. Assuming the efficiency of the wind turbine is only affected by wind velocity, Figure 2 shows the relationship between the efficiency of a windmill and wind velocity.

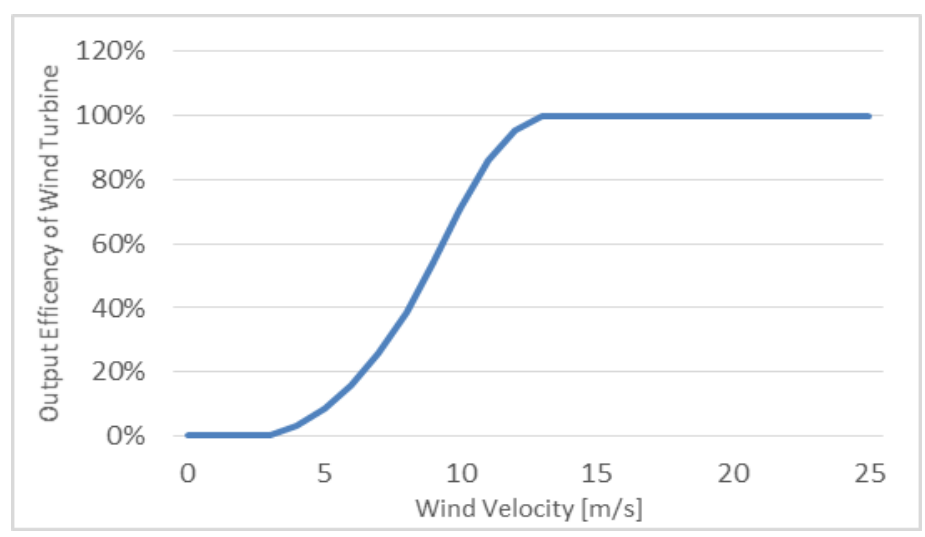

Figure 2 Efficiency of Wind Turbine Against Wind Velocity

Additionally, when the wind velocity is lower than $4 \mathrm{~m} / \mathrm{s}$ or higher than $26 \mathrm{~m} / \mathrm{s}$, the wind turbine cannot work for practical and safety purposes [11]. The wind velocity at each location at a certain time is converted to electric output following these rules. Hourly wind velocity in each place and time is obtained from the NEDO database "METPV-11" [12]. This data is then converted to the hourly average power output of wind turbines in each location. Using the data generated, 14 places with the best potential in each "Shicho" in Hokkaido are chosen as those locations with the best annual overall output. This gives the output from the wind turbines per kW capacity.

\section{Hydrogen demand and supply}

As well as electricity, hydrogen demand and supply should also balance. In terms of hydrogen demand, yearly hydrogen demand from FCV is calculated based on the yearly gasoline consumption per car in Hokkaido as shown in Eq. (3), when DPD [km /day • car] is the average running distance per car per day in Japan and $\varepsilon_{F C V}\left[\mathrm{~km} / \mathrm{Nm}^{3}\right]$ is the fuel efficiency of FCV.

$$
\sum_{t=1}^{24} C F C V_{(t)} \approx \frac{D P D}{\varepsilon_{F C V}}
$$

DPD is 25.82 [km / car - day] according to MLIT [13]. According to TOYOTA [14], the FCV they launched in 2014 has a hydrogen tank with $122 \mathrm{~L}$ capacity at $70 \mathrm{MPa}$ pressure, which is equivalent to $84.56 \mathrm{Nm}^{3}$. This car has a range of $650 \mathrm{~km}$ on one full tank. Thus, $\varepsilon_{-} F C V$ is set as $7.69 \mathrm{~km} \mathrm{/} \mathrm{Nm}^{3}$. Therefore $\sum_{t=1}^{24} C F C V_{(t)}$ is $3.357 \mathrm{Nm}^{3}$. In order to convert it into an hourly basis, this research assumes that the working hours of hydrogen stations are from gam to 9pm. While hydrogen is distributed only during working hours, hydrogen production can be at any time, according to wind conditions. And daily demand is distributed evenly throughout the day, because consumer's behaviour is uncertain and case-dependent. Thus the hydrogen demand per hour is simply 3.36 divided by 12 , so $\mathrm{CFCV}_{(\mathrm{t})}$ is $0.28\left[\mathrm{Nm}^{3} / \mathrm{h}\right]$ during gam and 9pm and other than that, it is set as o. By multiplying this by the number of FCV, the total hydrogen demand is determined.

From the perspective of hydrogen supply, this is provided using part of the electricity generated by the wind turbines. When $\mathrm{GenH}_{(t)}$ is the electricity utilized for hydrogen production at time $t$ and $H H V$ is the high heat value of hydrogen and Elecef is the efficiency of the electrolyser, the hydrogen supply at time $t$ is expressed as Eq.(4). $H H V$ is $3.54 \mathrm{kWh} / \mathrm{Nm}^{3}$ and Elecef is assumed as $80 \%$ following Mistushima and Matuzawa [15].

$$
\operatorname{GenH}_{(t)} \div \mathrm{HHV} \times \text { Elecef }
$$

In addition to these two factors, hydrogen demand and supply are accommodated by charge to and discharge from hydrogen storage onsite at the hydrogen station. Each station has $2100 \mathrm{Nm}^{3}$ storage as per [16]

\subsection{Economic Ripple Effect Analysis}

As one of the objectives of this research, the influence of the energy system on the local economy is analysed. When new demand is created by installation of a new energy system or its components, it causes demand for new production in other sectors. So, installing a wind turbine requires new production of components, such as steel and machines, as well as service requirements from other sectors. IO-table analysis is the method used here to estimate this production inducement effect. This 
inducement effect continues successively from demand in one sector to the other sectors, and can then flow on still further, but this research only estimates the first-level production inducement effect. The change in production is determined by the change in final demand and the change in exports using a Leontief inverse matrix, shown in Eq.(5), where $I$ is the identity matrix, $\bar{M}$ is the diagonal matrix of import rate of products, $A$ is a input coefficient table, $F$ is the final demand vector and $E$ is exports. In practice, as this energy system does not consider exports to other countries or regions, $\mathrm{E}$ is always zero.

$$
\{I-(I-\bar{M}) A\}^{-1}\{(I-\bar{M}) F+E\}
$$

In order to caluculate the economic ripple effect, the installed capacity of each component in the hydrogen energy system is converted to a final demand in monetary units. Firstly, by multiplying the unit price / cost of each component, the installation amount is converted to Japanese Yen. These demand factors are then connected to the relevant sectoral demand items in the IO-table. This process is described in Figure 3. At the time of installation of the hydrogen energy system, some demand factors, like demand for gasoline are anticipated to decrease due to their replacement with hydrogen. These replaced items are evaluated as reduced (negative) demand caused by the installation. On the other hand, capital items are anticipated to cause positive demand through requirements for parts and materials. Each item was investigated individually.

\begin{tabular}{|c|c|c|c|c|c|c|c|c|}
\hline \multicolumn{4}{|c|}{ Installation amount } & unit & & \multicolumn{2}{|c|}{ Installation amount in money unit } & unit \\
\hline \multirow{7}{*}{$\begin{array}{l}\text { Result from } \\
\text { Optimization } \\
\text { program }\end{array}$} & \multicolumn{3}{|l|}{ Electricity } & $\mathrm{kWh}$ & & \multicolumn{2}{|l|}{ Sales of Electricity } & \multirow{8}{*}{ JPY } \\
\hline & \multicolumn{3}{|l|}{ Hydrogen } & $\mathrm{Nm}_{3}$ & & \multicolumn{2}{|l|}{ Sales of Hydrogen } & \\
\hline & \multirow{2}{*}{\multicolumn{3}{|c|}{ Windmill Installation }} & $\mathrm{kW}$ & & \multirow{2}{*}{ Windmill Installation } & Capex & \\
\hline & \multirow{2}{*}{\multicolumn{3}{|c|}{$\begin{array}{l}\text { Number of hydrogen } \\
\text { station installation }\end{array}$}} & & & & Opex & \\
\hline & & & & - & & $\begin{array}{l}\text { Number of hydrogen station } \\
\text { installation }\end{array}$ & Capex & \\
\hline & \multirow{2}{*}{\multicolumn{3}{|c|}{ Electrolyzer installation }} & & & \multirow[b]{2}{*}{ Electrolyzer installation } & Capex & \\
\hline & & & & $\mathrm{kW}$ & & & Opex & \\
\hline $\begin{array}{l}\text { Scenario } \\
\text { Parameter }\end{array}$ & \multicolumn{3}{|c|}{ Number of FCV } & & & \multicolumn{2}{|l|}{ FCV } & \\
\hline \multicolumn{3}{|c|}{ Final demand description } & \multicolumn{2}{|c|}{$\begin{array}{c}\begin{array}{c}\text { ID in IO- } \\
\text { table }\end{array} \\
\end{array}$} & \multicolumn{4}{|c|}{ Index in IO-table } \\
\hline \multirow{17}{*}{$\begin{array}{c}\text { Created } \\
\text { Demand } \\
(+)\end{array}$} & \multirow{7}{*}{ Windmill } & \multirow{6}{*}{ Capex } & & & \multicolumn{4}{|c|}{ Coal products } \\
\hline & & & \multirow{2}{*}{\multicolumn{2}{|c|}{-38}} & \multirow{2}{*}{\multicolumn{4}{|c|}{$\begin{array}{l}\text { Pig iron and crude steel } \\
\text { Other metal products }\end{array}$}} \\
\hline & & & \multirow{2}{*}{\multicolumn{2}{|c|}{$\begin{array}{r}45 \\
49\end{array}$}} & & & & \\
\hline & & & & & \multicolumn{4}{|c|}{ Machinery for office and service industry } \\
\hline & & & \multicolumn{2}{|c|}{65} & \multirow{2}{*}{\multicolumn{4}{|c|}{ Reuse and recycling }} \\
\hline & & & & & & r vehicles and machine & & \\
\hline & & Opex & & & Repair of mo & r vehicles and machine & & \\
\hline & & & & & Metal produc & for construction and architect & & \\
\hline & Hydrogen & Capex & & & Other metal & oducts & & \\
\hline & Station & & & & Reuse and re & & & \\
\hline & & Opex & & o1 & Repair of mo & $\mathrm{r}$ vehicles and machine & & \\
\hline & & Capex & 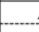 & & Other metal & oducts & & \\
\hline & Electrolyzer & & & & Reuse and re & cling & & \\
\hline & & Opex & & 01 & Repair of mo & r vehicles and machine & & \\
\hline & & & z & & Machinery fo & office and service industry. & & \\
\hline & FCV & Capex & & 51 & $\begin{array}{l}\text { Applied elect } \\
\text { instruments }\end{array}$ & nic equipment and electric me & suring & \\
\hline & & & & 99 & Other cars & & & \\
\hline & Oil fire $p$ & ower & & 8 & Final chemic & products, n.e.c. & & \\
\hline & & & & & Other metal & oducts & & \\
\hline Replaced & Gas Stat & & & & Reuse and re & cling. & & \\
\hline Demand & & & & 01 & Repair of mo & r vehicles and machine & & \\
\hline$(-)$ & Gasolir & & & 8 & Final chemic & products, n.e.c. & & \\
\hline & $\begin{array}{l}\text { Gasolir } \\
\text { Vehicl }\end{array}$ & & & 77 & Other electro & ic components & & \\
\hline
\end{tabular}

Figure 3 Conversion process of the results of the optimization program

As this research takes Hokkaido as a case study, the 2005 version of the IO table in Hokkaido is utilised from MLIT [17]. This IO table is a re-structured IO table specifically focusing on the economic activity in Hokkaido. Compared to the normal Japanese IO table, a small difference in the classifications of industry sectors can be seen. In this research, the utilized table has 109 sectors. In addition, this IO table distinguishes the imports and exports from/to foreign countries or other regions in Japan. The economic influence of the system is shown as the sum of the change in final demand and the economic ripple effect.

\subsection{Change in $\mathrm{CO}_{2}$ Emissions}

3EID includes the estimation of $\mathrm{CO}_{2}$ emissions from each industry per 1 million JPY production. Because the IO table indicates the change in economic activity of each industry, by using this inventory, it is possible to estimate the change of emissions from each industry when the classification of industries are identical in the inventory and IO-table. In the case study, the IO-table has 109 industry sectors, while the inventory only has 108 sectors based on the basic Japanese 108 sector IO-table. Thus, the inventory must be divided into 109 sectors before the analysis can be undertaken. The specific Hokkaido IO table separates "crops" in the IO table of Japan into "crops for eating" and "crops not for eating". Thus, the emissions of "crops" in the inventory are separated into two components equally weighted according to the "crops for eating" and "crops not for eating" in the IO table. The change in $\mathrm{CO}_{2}$ emissions caused by the energy system installation is estimated as the product of the economic influence of the system and the inventory.

\subsection{Evaluation of the result}

The optimization analysis is divided into three parts: configuration, calculation and evaluation of the results. Configuration was described in the previous section. Calculation is executed by using the GAMS software. The evaluation is to check whether the two conditions for hydrogen station installation are satisfied. The evaluation follows three criteria. Firstly, the size of the system is confirmed. This is judged from the amount of introduced wind turbines. The amount of wind turbines is simply determined by the sum of wind turbines in each place.

Then, in order to check whether the conditions to build hydrogen stations are satisfied, the Sales Profit Rate of the system is utilised as an indicator. The Sales Profit Rate is calculated by dividing the profit from the business model, which is the value of the objective function, by the total annualised cost of the system, which includes both running costs and depreciation expenses of the equipment. When this indicator is positive, initial investment will be recovered and further profit will be obtained after the project period (under the assumptions used in the model). The reason why this research uses a "rate" of sales profit is that the performance should not be measured by the size of the system because this research is specifically considering a system in the initial roll-out stages of FCV utilisation.

Finally, the profitability of hydrogen against running costs is evaluated. This corresponds with the condition of whether hydrogen-related equipment is utilized after it is built. This is determined by subtracting the running cost of the electrolyser and hydrogen station from the sales of hydrogen. When this indicator is positive, the operation of the hydrogen station has an incentive to be maintained under the situation where the initial investment has already been made.

The variables obtained through optimization are input into the IO-table and inventory model in order to complete the analysis. The results of these analyses is evaluated by the change in GDP and $\mathrm{CO}_{2}$ emissions in Hokkaido. 


\section{Results}

\subsection{Scenario Analysis: Number of FCV and Hydrogen ratio to electricity generation}

Characteristics of the energy system are analysed more comprehensively by using a range of values of FCV share in Hokkaido and the hydrogen production ratio compared with the total electric generation from wind turbines. FCV share is set at five levels: $1 \% / 5 \% / 10 \% / 15 \% / 20 \%$. Considering the number of gasoline vehicles in the residential sector in Hokkaido, these scenarios are equivalent to $27,000-540,000 \mathrm{FCV}$. The hydrogen ratio is set at seven levels: $1 \% / 5 \% / 10 \% / 15 \% / 20 \% / 25 \% / 30 \%$. By changing these two parameters, the feasibility of the system is evaluated for each combination.

Table 1 Feasibility of Each Scenario

\begin{tabular}{|c|c|c|c|c|c|}
\hline \multirow{2}{*}{$\begin{array}{l}\mathrm{H}_{2} \quad \text { vs } \\
\text { Electricity }\end{array}$} & \multicolumn{5}{|c|}{ Number of FCV } \\
\hline & $1 \%$ & $5 \%$ & $10 \%$ & $15 \%$ & $20 \%$ \\
\hline $1 \%$ & $\sqrt{ }$ & $x$ & $x$ & $x$ & $x$ \\
\hline $5 \%$ & $\sqrt{ }$ & $\sqrt{ }$ & $x$ & $x$ & $x$ \\
\hline $10 \%$ & $\sqrt{ }$ & $\sqrt{ }$ & $\sqrt{ }$ & $x$ & $x$ \\
\hline $15 \%$ & $\sqrt{ }$ & $\sqrt{ }$ & $\sqrt{ }$ & $\sqrt{ }$ & $x$ \\
\hline $20 \%$ & $\sqrt{ }$ & $\sqrt{ }$ & $\sqrt{ }$ & $\sqrt{ }$ & $\sqrt{ }$ \\
\hline $25 \%$ & $\sqrt{ }$ & $\sqrt{ }$ & $\sqrt{ }$ & $\sqrt{ }$ & $\sqrt{ }$ \\
\hline $30 \%$ & $\sqrt{ }$ & $\sqrt{ }$ & $\sqrt{ }$ & $\sqrt{ }$ & $\sqrt{ }$ \\
\hline
\end{tabular}

\section{Feasibility of the system}

Of the 35 scenarios developed with the above two parameters, 25 scenarios are successful in satisfying the constraints. The remaining 10 scenarios are found to be infeasible (shown in Table 1). Due to the assumption of not allowing electricity from outside of the business model to be used to produce hydrogen, when the demand for the electricity from wind turbines is too large, because wind turbine installation reaches the limit of potential [17], the system becomes infeasible. The demand for electricity from wind turbines is ultimately determined by the number of FCV, which determines the demand for hydrogen, and by the ratio of how much electricity is utilized for hydrogen production. From the definition of this ratio, when the ratio is low, electricity demand from wind turbines is high.

\section{Size of the system}

The size of the energy system installation is influenced by both scenario parameters as shown in Figure 4. From the perspective of FCV share, the greater the number of FCV, the more wind turbines are installed. The relationship between hydrogen ratio and the size of the system is approximately linear, though it is disturbed by the influence of the characteristics of hourly wind and the upper limit of wind turbines in 14 places.

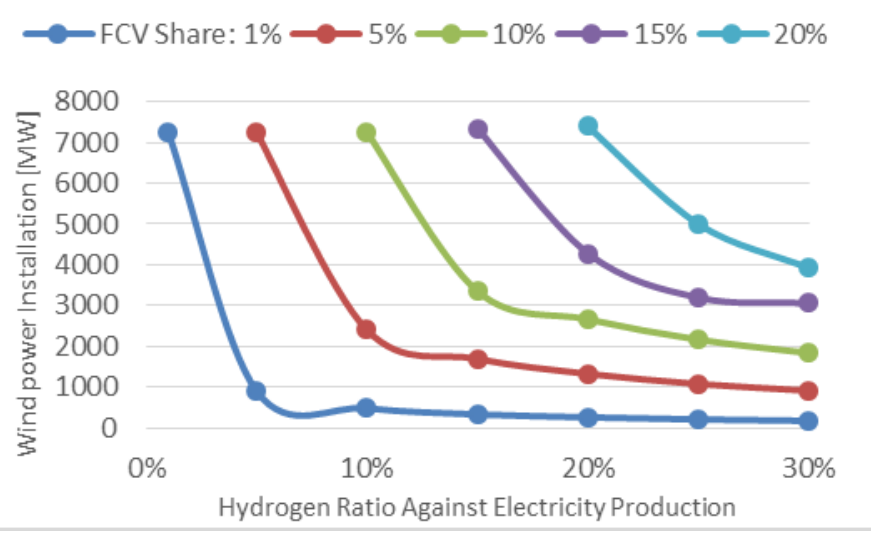

Figure 4 Wind turbine installation trend with FCV share and hydrogen:electricity ratio

\section{Sales Profit Rate}

From the results shown in Figure 5, from the perspective of sales profit rate there appears to be a peak or optimum for each share of FCV tested, after which the sales profit rate declines in a similar fashion for increasing hydrogen ratio. This indicates that after the FCV share-specific peak, sales profit rate is almost unaffected by FCV share, which suggests that hydrogen ratio is the dominant factor of this system.

Another interpretation of the result is that the sales profit rate faces a trade-off between flexibility of hydrogen production and the upper limit of wind turbine installation. When hydrogen ratio is high, hydrogen production is more likely to be affected by the intermittency of wind power. Thus, the lower the hydrogen ratio is, the higher the sales profit ratio is. On the other hand, from the viewpoint of wind turbine allocation, locations with strong wind are prioritized. However, when the hydrogen ratio is lower, in order to supply electricity to the grid, places with lower efficiency have to be utilized as well. The curve shown in Figure 5 represents the trade-off between these two factors.

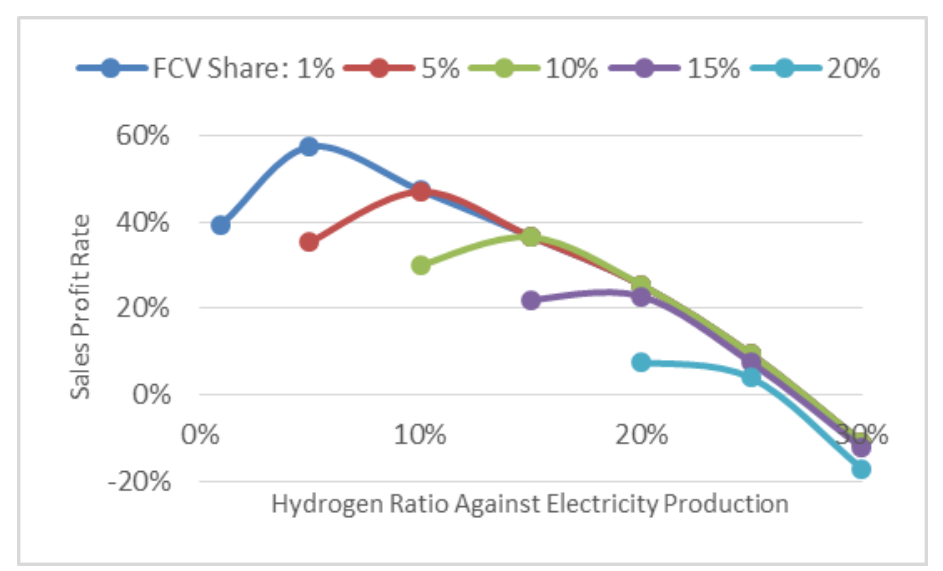

Figure 5 Sales Profit Rate

Another interpretation of this result is that the sales profit rate faces a trade-off between flexibility of hydrogen production and the upper limit of wind turbine installation. When the hydrogen ratio is high, hydrogen production is more likely to be affected by the intermittency of wind power. Thus, the lower the hydrogen ratio is, the higher sales profit ratio is. On the other hand, from the point of wind turbine allocation, places with strong wind are prioritized. However, when the hydrogen ratio is lower, in order to 
supply electricity to the grid, place with lower efficiency have to be utilized as well. The curve shown in Figure 5 represents the trade-off between these two factors.

\section{Profitability of Hydrogen}

Profitability of hydrogen is evaluated as the profit per hydrogen station - this measure is chosen so that the evaluation is not affected by the total installed capacity. The profit is defined as the hydrogen sales minus the operational expenditure of the electrolyser and hydrogen station. The results are shown in Figure 6. The change in the profitability of hydrogen is, as shown in Figure 7 , affected by the capacity factor of the hydrogen station. The capacity factor of a hydrogen station is defined by Eq.(6), where $C F_{s t}$ is the capacity factor of a hydrogen station, $W H$ is the accumulated working hours of the hydrogen station through the year, which is 4380 because in this research the working hours of hydrogen stations are set as 12 hours a day, $\operatorname{Cap}_{s t}$ is the hourly capacity of the hydrogen station to supply hydrogen, which is set as $300 \mathrm{Nm}^{3}$ considering METI [18] and $\mathrm{NoS}$ is the number of hydrogen station.

$$
C F_{s t}=\frac{\text { Supply }_{H 2}}{W H * \operatorname{Cap}_{s t} * N o S}
$$

In this research, because the storage capacity of hydrogen is determined by the number of hydrogen stations, the capacity to accommodate the gap between the supply from wind power and the demand from FCV is determined by the number of hydrogen stations. As seen in Figure 7, the capacity factor of hydrogen stations decreases with the hydrogen ratio. This is because the higher the hydrogen ratio is, the more the intermittency of wind restricts the behaviour of wind power and electrolyser. Then because hydrogen stations cannot provide hydrogen on demand, more hydrogen stations are necessary in order to increase the amount of hydrogen storage. The higher number of hydrogen stations leads to higher running costs. When the hydrogen ratio is $30 \%$, no FCV share can achieve the conditions required for hydrogen station utilization.

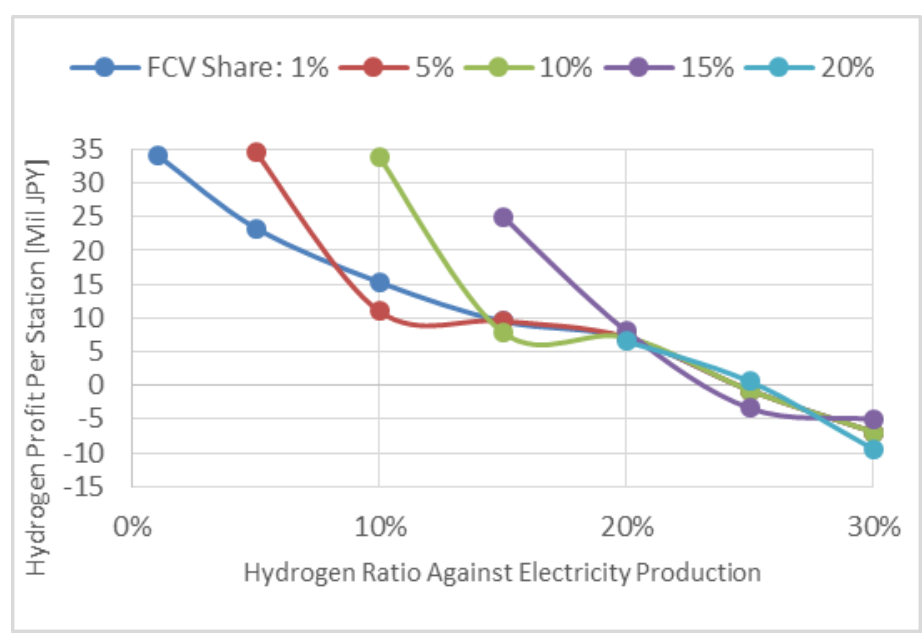

Figure 6 Hydrogen Profit per Station

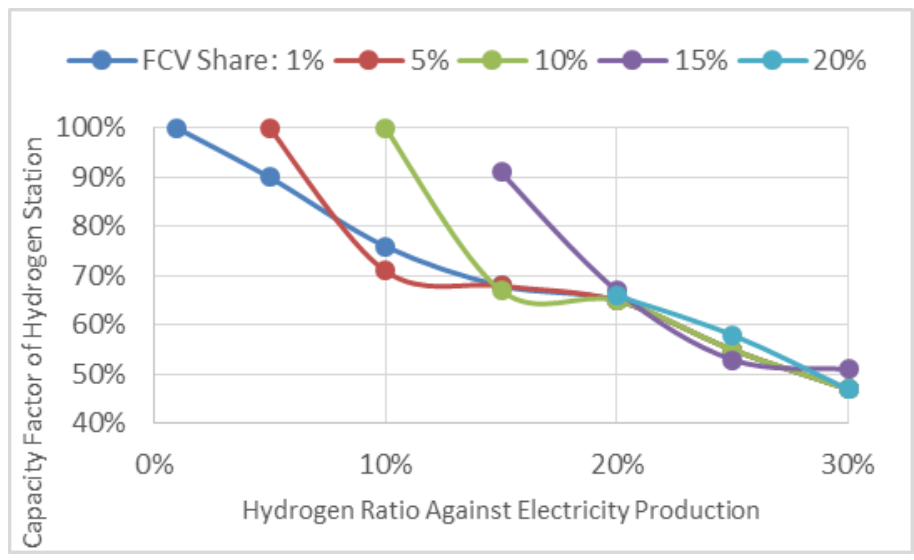

Figure 7 Capacity Factor of Hydrogen Station

On the other hand, when the FCV share is high the absolute number of hydrogen stations, and thus the amount of hydrogen storage, is higher. However, at the same time (as shown in Figure 8 ), the larger the size of the system, the greater the installation of wind turbines and the lower the capacity factor of wind turbines. This is because when the amount of hydrogen required is larger, wind turbines will be constructed not only in the areas of best wind conditions, but also in places with lower wind capacity.

\subsection{Marginal Cost of Hydrogen Production}

In this model, wind power and hydrogen stations are integrated so there is no need to buy electricity from outside to produce hydrogen. Moreover, using wind power the marginal cost for hydrogen production is almost zero. On the other hand, in the case where the hydrogen production is combined with thermal power plant or relies on the purchase of electricity from the grid, it is necessary to procure electricity with the cheapest marginal cost. Thus, the significance of wind power in this model is examined by showing the breakeven marginal cost of electricity for hydrogen production in order to satisfy the condition of utilization of the hydrogen station. The results are shown in Figure 9.

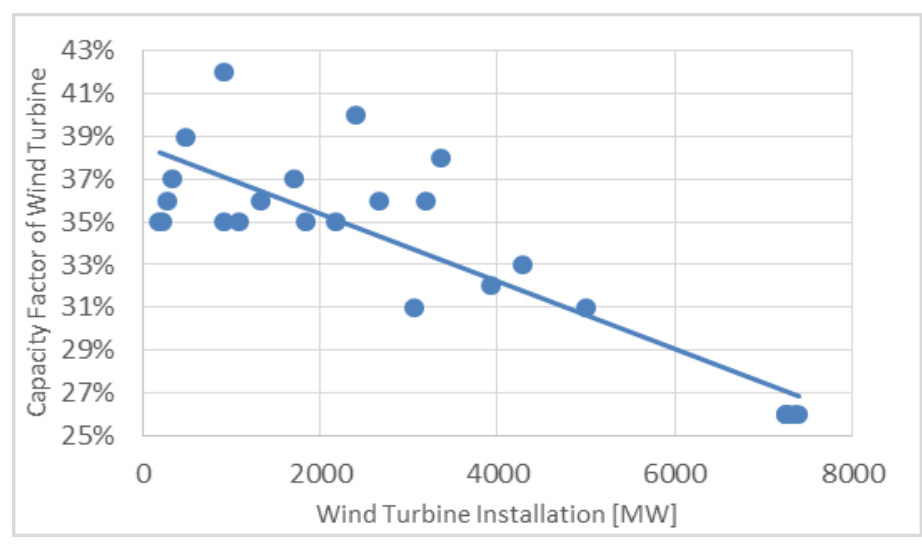

Figure 8 Average Capacity Factor of Wind Turbines 


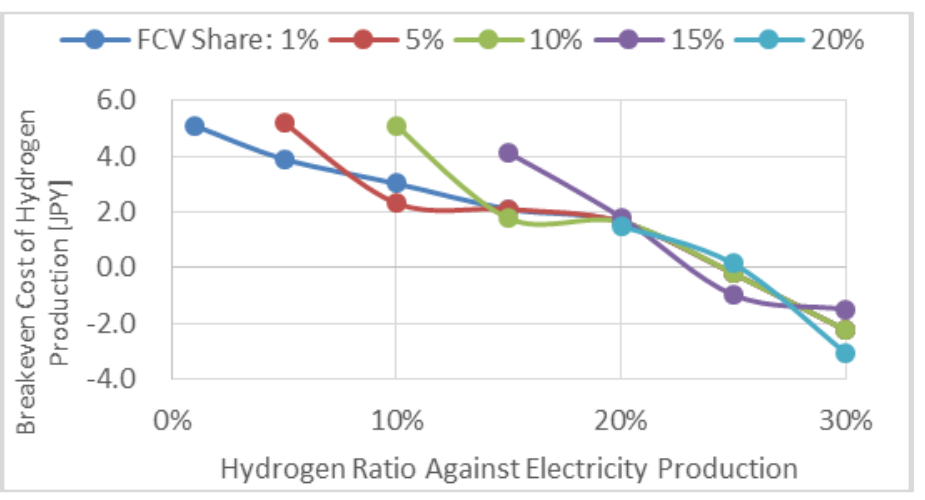

Figure 9 Breakeven Cost of Hydrogen Production

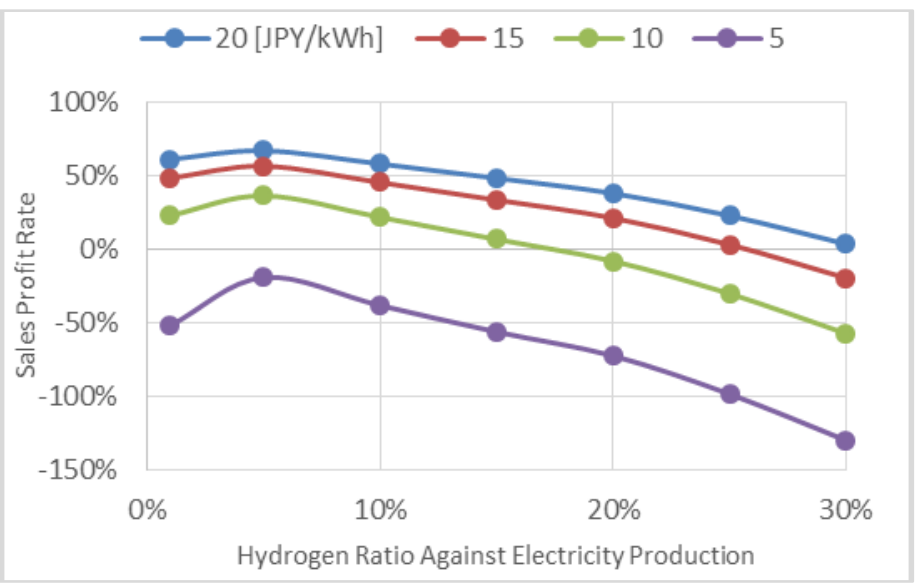

Figure 10 Sales Profit Rate and Electricity Price

As the hydrogen ratio increases, the breakeven cost decreases, as the profit itself decreases. From these results, buying electricity from outside can be seen as not suitable in most practical cases for this hydrogen energy model. Even when the hydrogen ratio is as low as $1 \%$, the required marginal cost in order to break even is 5.1 JPY / kWh. Judging from the current wholesale electricity prices, this would be difficult to achieve. Moreover, combining with other electricity generation technologies is also typically not suitable for example, the marginal cost of coal-fired power is calculated as 5.1 JPY / kWh [6]. Therefore, it is difficult to construct an economically feasible hydrogen station model combined with electricity sources other than renewable energies with low marginal cost, represented by wind power in this paper.

\subsection{Additional analysis on Electricity Price Impact}

The influence of electricity price on sales profit rate was further examined in order to understand more of the dynamics of the system. By fixing FCV share as $1 \%$, the change in sales profit against various electricity prices was analysed shown in Figure 10. When the electricity price is $5 \mathrm{JPY} / \mathrm{kWh}$, there is no hydrogen ratio that can achieve a positive sales profit rate, while when electricity is $20 \mathrm{JPY} / \mathrm{kWh}$, the sales profit rate is positive regardless of the hydrogen ratio. When the electricity price is low, the system may only remain profitable by decreasing the rate of hydrogen production (under the conditions of this model).

\subsection{Economic Influence on Hokkaido}

The results of economic ripple effect analysis show that in all scenarios in this study, the influence on Hokkaido's economy is positive (as shown in Figure 11). In addition, the magnitude of the influence is dependent on the FCV share. The economic influence can be divided into two components: the final demand and the economic ripple effect. These two factors have different tendencies when compared to each other (As shown in Figure 12). With regard to final demand, when the hydrogen ratio is low, the negative influence caused by replacement of oil is larger than the economic influence of new created demand. Regarding the economic ripple effect, on the other hand, because the supply chain of wind turbine installation is assumed to be mainly inside Hokkaido, while the oil supply chain is not, as the hydrogen ratio increases, the production inducement also increases. In total, the positive influence exceeds the negative.

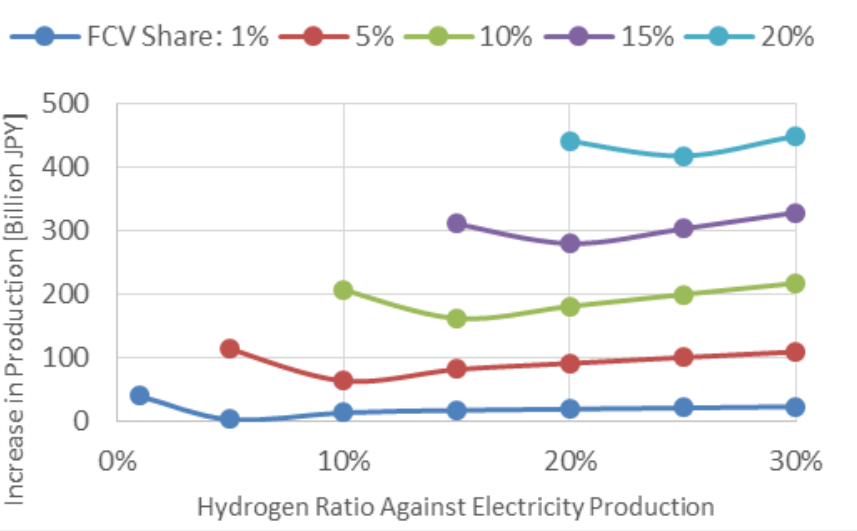

Figure 11 Economic Influence of the Energy System on Hokkaido

In all the analysed scenarios in this study the energy system contributes to the reduction of $\mathrm{CO}_{2}$ emissions within Hokkaido (as shown in Figure 13). This impact can also be divided into the contribution from final demand and from production inducement effect (as shown in Figure 14). As with the economic impact, these two factors have also different tendencies. The change in final demand creates a significant reduction of $\mathrm{CO}_{2}$ emissions because of the reduction of oil caused by the replacement of oil-based electricity with wind power. On the other hand, the economic ripple effect leads to an increase in economic activity, which ultimately increases $\mathrm{CO}_{2}$ emissions even though the emissions factor for energy utilised in industry decreases from the current energy system. In total, because the influence caused by the direct oil replacement is larger, there is a net $\mathrm{CO}_{2}$ emission reduction in all scenarios.

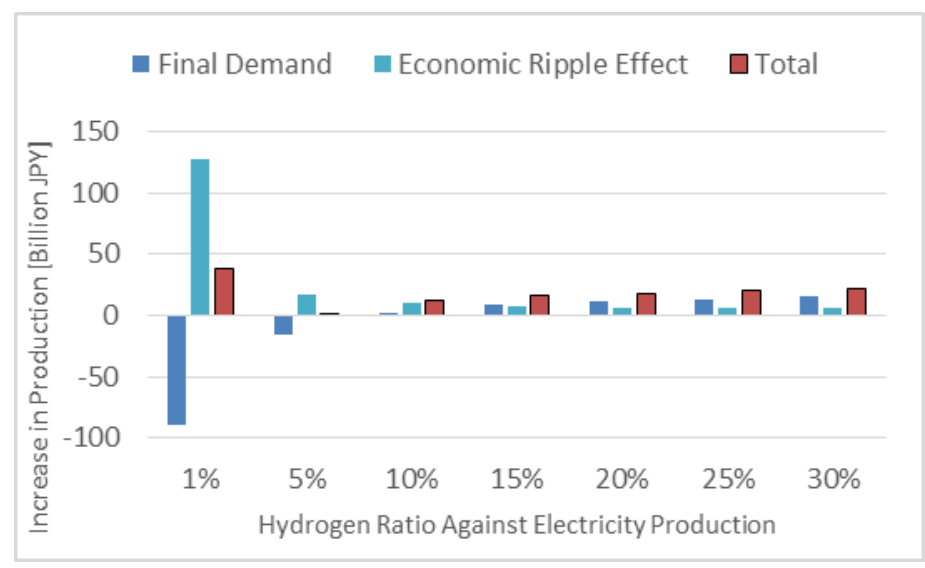

Figure 12 Impact Analysis of Economic Influence 


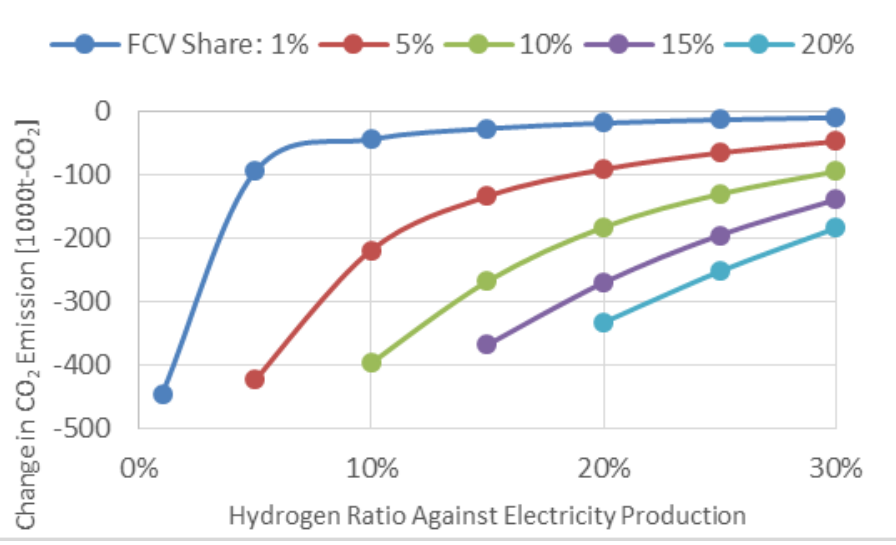

Figure 13 Change in $\mathrm{CO}_{2}$ Emissions Caused by the Energy System

\subsection{Change in $\mathrm{CO}_{2}$ emissions}

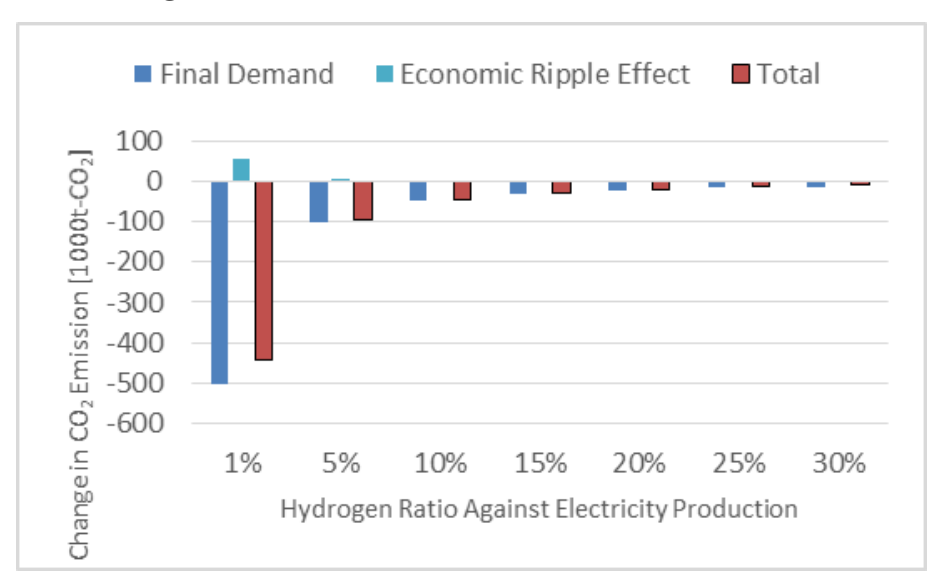

Figure 14 Impact Analysis of $\mathrm{CO}_{2}$ Emissions

\section{Discussion}

Through this analysis, the feasibility of the energy system from the business model and macroscopic viewpoints were examined.

From the perspective of the feasibility of the business model, it is analysed from two viewpoints: installation and utilization. The first is indicated to be unrelated to the size of the installation as long as it does not reach the upper potential limit of wind power. It is highly influenced by the electricity price.

The second point is affected by the number of hydrogen stations, which fill the dual role as storage. When the hydrogen ratio against electricity is low, the flexibility of hydrogen production is high, which leads to lower requirement for hydrogen stations and, thus, higher profitability of hydrogen. In terms of the share of FCV, a simple, clear relationship with hydrogen profitability could not be confirmed. Instead it is affected by the magnitude of wind turbine installation, because when wind turbines are allocated, the places with better wind potential are prioritized however, as the system size increases, the total capacity factor of wind turbines decreases as lower wind potential sites are utilised. This indicates that the considered business model specifically suits for the beginning stages of hydrogen introduction, as it may only work effectively when wind turbines are allocated to places with superior wind conditions. Despite its overall high potential for wind power, such locations are limited even in Hokkaido.
From the viewpoint of macroscopic influence, in all scenarios the influence on local GDP and on the $\mathrm{CO}_{2}$ emissions are positive. Specifically, the dominant factor of economic influence is FCV share. In terms of $\mathrm{CO}_{2}$ emissions, the dominant factor is the replacement of oil by wind power. The FCV share, determines the demand for electricity from wind power so the larger the share, the larger the impact.

There are a number of limitations to this study, which would offer scope for further development. Firstly, the risk of the model is not discussed sufficiently, considering investment risk and other socio-economic risks. The research does not consider the possible change in economic environment and conditions of support after the investment is complete. Thus, the robustness of the system already built should be further discussed including, for example, the possible change of demand and supply. From the perspective the of hydrogen energy system, this research regarded the number of FCV as given. However, FCV are still expensive and especially at the beginning, due to the lack of infrastructure, there may be barriers for installation. The possible behaviour of both consumers and the business model should be analysed, as a means of examining the transitional performance of moving towards a hydrogen economy.

\section{Conclusions}

Throughout this study, the feasibility of the hydrogen station installation model is analysed from the viewpoints of business model, influence on the local economy and the change in $\mathrm{CO}_{2}$ emissions.

This research has two key conclusions. One is that, by dividing the business model into investment and utilization, the lower marginal cost of wind power is evaluated as useful - especially at the beginning of hydrogen station installation. Once the hydrogen station is built, it is likely to be utilized when it is integrated with the wind power business model.

The other is that, as long as the energy system model is feasible from the viewpoint of the business model, it also has positive impact on local economy and on $\mathrm{CO}_{2}$ emissions. This finding may provide the incentive for local/ national governments to aid or subsidise the installation of the system in order to activate the local economy and reduce $\mathrm{CO}_{2}$ emissions, which would makes it easier to achieve this energy system.

\section{References}

[1] METI 工 Energy Hakusho

[2] METI.

[2] METI. 総合資源調査会原子力小委員会第三回会合参考資料 1 , 2014.

http://www.meti.go.jp/committee/sougouenergy/denkijigyou/ genshiryoku/pdf/o03_so1_oo.pdf. Accessed 24th March 2016.

[3] Kochi Prefecture. IO table of Kochi Prefecture 2010, 2014. http://www.pref.kochi.lg.jp/soshiki/111901/2014061400035.html. Accessed 24th March 2016.

[4] UNFCCC. INDC-Submissions, 2015 http://www4.unfccc.int/submissions/indc/Submission\%2oPag es/submissions.aspx. Accessed 24th March 2016.

[5] MOE. Annual Report on the Environment, the Sound Material-

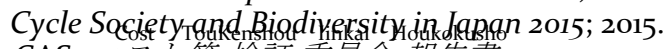

[6] CAS. ב ב c

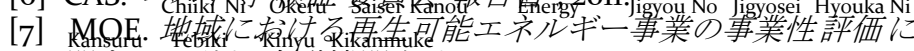
関する手引き(金融機関向け) Ver 1.1; 2014

[8] Seiji S. Fuel Cell Vehicle Development and Initial Market Creation, 2015 . https:/www.iea.org/media/workshops/2014/asiahydrogenwor kshop/SessionIISanoToyotaFCEVdevelopment.pdf. Accessed 6th May, 2016. 
[9] Jeff P. Electric Cars Can't Take the Cold, 2015. http://www.bloomberg.com/news/articles/2015-12-03/electric-

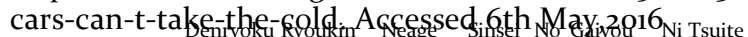

[10] HEPCO. 電力 料金值Eげ申請の概要について, 2015 http://www.hitachi.co.jp/products/power/wind-

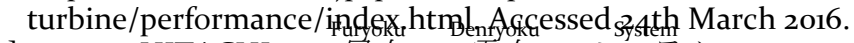

[11] HITACHI. 風力電力 矤テム , 2013 http://www.hitachi.co.jp/products/power/windturbine/performance/index.html. Accessed 24th March 2016.

[10] NEDO. $M E T P V-11$, 2015 . http://www.nedo.go.jp/library/nissharyou.html?from=b.

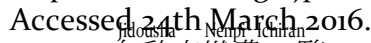

[11] MLIT, 自動車燃費一覧. 2014. Shuyo Shogenhyou

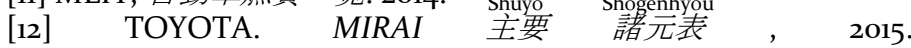
http://toyota.jp/pages/contents/mirai/oo1_p_oo1/pdf/spec/mir ai_spec_201501.pdf. Accessed 24th March 2016.

[13] Shigenori M, Koighhiso M. Presentsteghhnoligies and subjects of

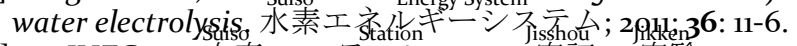

[14] JHFC. 水素 ステーション矢証実験， 2007 http://www.jari.or.jp/Portals/o/jhfc/data/seminor/fy2007/pdf/ h19_2.pdf. Accessed 24th March 2016.

[15] MLIT. IO table of Hokkaido Prefecture 2010, 2014. http://www.hkd.mlit.go.jp/topics/toukei/renkanhyo/renkan.ht $\mathrm{ml}$. Accessed 24th March 2016.

[16] Keisuke N, Yuichi M. Embodied energy and emission intensity data for Japan using input-output tables (3EID): For 2005 IO table, 2012. http://www.cger.nies.go.jp/publications/report/do31/index.ht $\mathrm{ml}$. Accessed 24th March 2016.

[17] JWPA. 風力発電の導入ポテンシャルと電力系統連携対策. 2009 [cited 2016 4th February]; Available from:

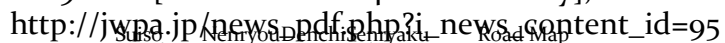

[18] METI. 水素・燃料電池戦略ロードマップ.2014 